\title{
Immature Doublecortin-Positive Hippocampal Neurons Are Important for Learning But Not for Remembering
}

\author{
Jana Vukovic, ${ }^{1}$ Gilyana G. Borlikova, ${ }^{1}$ Marc J. Ruitenberg, ${ }^{1,2}$ Gregory J. Robinson, ${ }^{1}$ Robert K.P. Sullivan, ${ }^{1}$ \\ Tara L. Walker, ${ }^{1}$ and Perry F. Bartlett ${ }^{1}$ \\ ${ }^{1}$ Queensland Brain Institute, and ${ }^{2}$ School of Biomedical Sciences, The University of Queensland, Brisbane, Queensland 4072, Australia
}

It is now widely accepted that hippocampal neurogenesis underpins critical cognitive functions, such as learning and memory. To assess the behavioral importance of adult-born neurons, we developed a novel knock-in mouse model that allowed us to specifically and reversibly ablate hippocampal neurons at an immature stage. In these mice, the diphtheria toxin receptor (DTR) is expressed under control of the doublecortin (DCX) promoter, which allows for specific ablation of immature DCX-expressing neurons after administration of diphtheria toxin while leaving the neural precursor pool intact. Using a spatially challenging behavioral test (a modified version of the active place avoidance test), we present direct evidence that immature DCX-expressing neurons are required for successful acquisition of spatial learning, as well as reversal learning, but are not necessary for the retrieval of stored long-term memories. Importantly, the observed learning deficits were rescued as newly generated immature neurons repopulated the granule cell layer upon termination of the toxin treatment. Repeat ( or cyclic) depletion of immature neurons reinstated behavioral deficits if the mice were challenged with a novel task. Together, these findings highlight the potential of stimulating neurogenesis as a means to enhance learning.

\section{Introduction}

Hippocampal neurogenesis is widely thought to be critical for certain aspects of learning and memory throughout life. Adultborn neurons are generated from a pool of precursor cells within the subgranular zone of the dentate gyrus before maturing and integrating into the hippocampal circuitry (van Praag et al., 2002; Trouche et al., 2009). Adult-born immature neurons, including the doublecortin (DCX)-expressing population, have been hypothesized to underpin ongoing learning and memory formation as these cells are highly excitable (Karl et al., 2005) and have lower thresholds for activation and induction of long-term potentiation than mature granule cells (Wang et al., 2000; SchmidtHieber et al., 2004; Ge et al., 2007; Cheng et al., 2011).

To date, most studies aiming to deplete immature neurons have induced sustained interruption of the neurogenic process at the level of the multipotent neural precursors by irradiation, antimitotic agents, or transgenic mouse models (e.g., Saxe et al., 2006; Deng et al., 2009; Garthe et al., 2009; Arruda-Carvalho et

\footnotetext{
Received June 25, 2012; revised Feb. 26, 2013; accepted March 4, 2013

Author contributions: J.V., G.G.B., and P.F.B. designed research; J.V., G.G.B., M.J.R., G.J.R., R.K.P.S., and T.L.W. performed research;P.F.B. contributed unpublished reagents/analytic tools; J.V., G.G.B., M.J.R., and P.F.B. analyzed data; J.V., G.G.B., and M.J.R. wrote the paper.

This work was supported by a National Health and Medical Research Council Program Grant and ARC Special Research Initiative in Stem Cells Science (SR110001002), to P.F.B. and the Estate of Dr. Clem Jones AO. J.V. was supported by the Queensland Government Smart Futures Fellowship. M.J.R. was supported by a SpinalCure Australia Career Development Fellowship. We thank the staff of the University of Queensland Biological Resources facility for breeding and maintaining the animals used in this study; Estella Newcombe and Deaglan Barnes for technical assistance; Ashley Cooper and Rowan Tweedale for editorial assistance; and Dee McGrath for assistance with illustrations.

The authors declare no competing financial interests.

Correspondence should be addressed to Dr. Perry F. Bartlett, Queensland Brain Institute, University of Queensland, Brisbane, QLD 4072, Australia. E-mail: p.bartlett@uq.edu.au.

DOI:10.1523/JNEUROSCI.3064-12.2013

Copyright $\odot 2013$ the authors $\quad 0270-6474 / 13 / 336603-11 \$ 15.00 / 0$
}

al., 2011), thereby ablating the different cell lineages along the neurogenic path. Using these approaches, a number of studies have consequently reported poor performance in different behavioral aspects of hippocampal-dependent tasks (e.g., the Morris water maze and contextual fear conditioning) (Saxe et al., 2006; Deng et al., 2010; Goodman et al., 2010), suggesting that adult-born neurons are involved in extracting critical information, such as spatial location and context from the environment during learning. Consensus is yet to be reached, however, on the precise timing and specificity of behavioral deficits that result from blocking neurogenesis (Deng et al., 2010), and on the contribution of immature neurons to these behavioral outcomes.

In this study, we generated a novel knock-in $D C X^{D T R}$ mouse line to more directly test the premise that immature neurons in the dentate gyrus are important for particular aspects of spatial learning and memory formation. In these mice, the diphtheria toxin receptor (DTR) is expressed under control of the DCX promoter, which allows for specific ablation of DCX-expressing immature neurons after administration of diphtheria toxin (DT) while leaving the neural precursor pool and its non-neuronal progeny intact. Upon cessation of treatment, the immature neuronal population can therefore be regenerated from the unaffected precursor pool.

We used transient ablation in combination with active place avoidance, a hippocampus-dependent task (Cimadevilla et al., 2001; Wesierska et al., 2005) that has been shown to be more sensitive to learning impairments than the water maze test (Cimadevilla et al., 2001; Kubik and Fenton, 2005), to test the significance of immature neurons for behavior. To identify potential differences resulting from ablation of neurogenesis, we designed a challenging training protocol that reduced the number of trials 
per day to further increase the cognitive demands of the test. Our findings indicate that immature neurons expressing DCX are required for mastering a novel spatial task; however, they are not necessary for recall of a learned spatial task. Importantly, subsequent repopulation of the immature DCX-expressing neurons rescues an animal's ability to learn a new task.

\section{Materials and Methods}

\section{Animals}

To ablate DCX-positive $\left(\mathrm{DCX}^{+}\right)$neurons, we generated a knock-in mouse model in which DTR was expressed under the control of the endogenous DCX promoter sequence via an internal ribosome entry site (IRES) sequence. For this, a targeting vector containing an ires-venus-dtr fusion gene was inserted via homologous recombination into the $3^{\prime}$ untranslated region of the $d c x$ genomic locus, behind the TGA stop codon in exon 7 of the $d c x$ gene (NM_010025 located on the X chromosome; Ensembl gene ID: ENSMUSG00000031285). DCX ${ }^{D T R}$ mice were produced by Ozgene. In brief, the sequences for ires (forward primer: $5^{\prime}$-CGGTCTCTGGTGATGCCATTTC3'; reverseprimer:5' -TCCTCGCCCTTGCTCACCATGGTTGTGGCCATA TTATCATCGTG-3'; $776 \mathrm{bp}$ ), the reporter Venus (forward primer: $5^{\prime}$-AT GGTGAGCAAGGGCGAGGA-3'; reverse primer: 5'-CTTGTACAGCTC GTCCATGCCG-3'; $717 \mathrm{bp}$ ), and $d t r$ (forward primer: $5^{\prime}$-CGGCATGGAC GAGCTGTACAAGATGAAGCTGCTGCCGTCGG-3'; reverse primer: 5' CATCGATTAATTAATCAGTGGGAATTAGTCATGCCCAA-3'; 663 bp) were amplified from existing constructs with overlap, fused by PCR, and cloned into the ClaI site of the Ozgene plasmid PacL, which was used for construction of the targeting vector. The final fusion product contained an EcoR V restriction site for genomic screening, together with ClaI and NotI sites for cloning. The $5^{\prime}$ homology arm was amplified from genomic C57BL/6 mouse DNA (forward primer: $5^{\prime}$-GTATTATGTCTCTTATACCT TACTAAACCCCGTT-3'; reverseprimer:5'-CGCGGCCGCTAGGCTTTG ATTTAGCCTATCATCTTTCAC-3'; 7085 bp) and contained a NotI site for cloning. The $3^{\prime}$ homology arm was similarly amplified from genomic C57BL/6 DNA (forward primer: 5'-CGCGGCCGCATCGATAGTACTTAT TGTAGCAGAATACTTTCGCTCAAGTG-3'; reverseprimer:5' -CGCGGC CGCGAAAGCCTTG CTGCAAAGAAACC-3'; 3992 bp) and contained an ScaI site for genomic screening, as well as ClaI and NotI sites for cloning purposes. Cloning of these homology arms upstream and downstream of the ires-venus- $d t r$ fusion fragment completed the targeting vector construct. The correctness of all fragments used for cloning and the final construct was confirmed through sequencing. Next, the targeting vector was excised through digestion with PvuI, and the resulting linearized fragment $(16.6 \mathrm{~kb})$ was purified and microinjected into embryonic stem cells. Successful insertion and correct targeting were confirmed through digestion with EcoRV, which yielded an $8.4 \mathrm{~kb}$ fragment and an $8.8 \mathrm{~kb}$ fragment for the mutant allele (with the latter including the ires-venus- $d$ tr fusion fragment) rather than a single $15.2 \mathrm{~kb}$ fragment for the untargeted genomic locus. The identity of these fragments was confirmed through Southern blot hybridization. For this, specific probes were generated through PCR using the forward $5^{\prime}$-CT GTTTCTTTCCTTCCAGTG- $3^{\prime}$ and reverse $5^{\prime}$-CTTGTGGGTGTAGAGA TAGG-3' primers for the upstream $8.4 \mathrm{~kb}$ fragment (yielding a $629 \mathrm{bp}$ product), or the forward 5'-TCTGCCATTTTGTGAACGGTG-3' and reverse 5'-GACATTGACATCCCCAAGGTTTC-3' primers for the downstream $8.8 \mathrm{~kb}$ fragment (yielding a $536 \mathrm{bp}$ product). Although the coding sequence for the reporter gene venus was inserted before the $d t r$ sequence, it was found to be nonfunctional as no native fluorescence was observed. $D C X^{D T R}$ knock-in mice were bred on a C57BL/6J background and backcrossed for more than seven generations. Male mice, 7-10 weeks of age, were used for all experiments. Mice were handled for $\sim 3$ min per day for $3 \mathrm{~d}$ before the beginning of behavioral experiments. Controls were nonlittermate wild-type (WT) mice on the same genetic background that were housed under similar conditions to the $D C X^{D T R}$ mice. In the active place avoidance task, after DT injection, these nonlittermate WT mice performed similarly to WT mice that were generated directly from heterozygous $D C X^{D T R}$ breeding pairs $\left(F_{(1,12)}=0.10, p=0.75\right)$. All experiments were conducted in accordance with the Australian Code of Practice for the Care and Use of Animals for Scientific Purposes, with approval from the University of Queensland Animal Ethics Committee. Animals were maintained under standard conditions on a 12-h light/dark cycle (lights on at 7:00 A.M.) with food and water provided ad libitum. All experiments were conducted between 9:00 A.M. and 5 P.M.; animals were grouphoused with 2-5 animals per home cage.

\section{Drugs}

To deplete $\mathrm{DCX}^{+}$cells, $10 \mathrm{ng}$ DT (Sigma) per gram of bodyweight was intraperitoneally injected every second day over a period of $11 \mathrm{~d}$ (i.e., 6 injections total), except during optimization of the delivery paradigm, when DT was injected daily $(10 \mathrm{ng} / \mathrm{g})$ for $10 \mathrm{~d}$. In all experiments, both WT and $D C X^{D T R}$ mice were treated with DT to ensure group effects could not be attributed to nonspecific effects of the toxin. We initially tested an alternative DT delivery regime (i.e., the optimization paradigm), with which we observed a significant reduction in percentage weight change. Daily DT injection resulted in significant weight loss $(13.3 \pm 3.3 \%)$ on day 9 and thereafter compared with the starting weight before DT treatment. The average weight of the mice was not significantly different between genotypes after DT treatment on any of the days, including day 9 (WT: $25.7 \pm 1.2 \mathrm{~g}$ vs $D C X^{D T R}: 22.48 \pm 2.2 \mathrm{~g} ; p=0.22$ ). The negative effect of daily DT treatment was also reflected in reduced total distance covered in the open field behavioral task and a delay in the response to the nociceptive stimulus in the hot-plate test for $D C X^{D T R}$ compared with WT mice (data not shown). For this reason, the daily treatment was not used for any of the behavioral experiments. In contrast, treatment every second day did not produce adverse effects (i.e., no change in weight or explorative behavior). As a result, this protocol was used for all experiments in this study.

\section{Cell culture}

Cortical neuronal cultures. A small piece of dorsolateral cerebral cortex was dissected from postnatal day 1 (P1) WT and $D C X^{D T R}$ mice. The tissue was then minced with a scalpel and dissociated in $1 \mathrm{ml}$ of $0.05 \%$ trypsin (Invitrogen) for $6 \mathrm{~min}$ at $37^{\circ} \mathrm{C}$. Next, $1 \mathrm{ml}$ of trypsin inhibitor was added and the tissue was triturated into a single-cell suspension. The sample was washed with $15 \mathrm{ml}$ of Eagle's minimum essential medium and passed through a $40 \mu \mathrm{m}$ filter, then spun at $100 \mathrm{~g}$ for $7 \mathrm{~min}$, and the pellet suspended in culture medium (DMEM containing 10\% fetal calf serum). The cells were plated in an 8-well chamber slide coated with poly-L-lysine $(0.1 \mathrm{mg} / \mathrm{ml}$; Sigma) at 20,000 cells/well, with each sample being plated across two duplicate wells. At the time of plating, DT was added at $50 \mathrm{ng} / \mathrm{ml}$ and the cells were cultured for $4 \mathrm{~d}$ at $37^{\circ} \mathrm{C}$ under $5 \%$ $\mathrm{CO}_{2}$. Next, the cells were fixed with $4 \%$ paraformaldehyde (Sigma) in 0.1 $\mathrm{M}$ PBS. After washing with PBS, the cells were incubated for $1 \mathrm{~h}$ at room temperature (RT) with blocking solution: $5 \%$ fetal calf serum plus $5 \%$ normal goat serum (Sigma-Aldrich) in $0.1 \mathrm{M}$ PBS containing $0.1 \%$ Triton X-100 (Sigma). The blocking solution was replaced with fresh solution containing monoclonal mouse anti-DCX antibody (1:500; Abcam), and the cells were incubated in this fresh solution for $1 \mathrm{~h}$ at RT. Cells were washed with PBS and incubated for $30 \mathrm{~min}$ at RT in blocking solution containing AlexaFluor-488 anti-rabbit antibody (1:1000; Invitrogen). After washing with PBS, slides were coverslipped with fluorescence mounting medium (Dako Cytomation) containing DAPI (1:5000; Sigma). The cells were viewed on a Zeiss inverted fluorescence microscope and the number of DCX-expressing cells quantified across five random fields per well.

Differentiation of subventricular zone neurospheres. To assess depletion of DCX ${ }^{+}$cells in culture, DT was added to differentiated subventricular zone (SVZ) neurospheres. In brief, adult mice $(n=4)$ were killed by cervical dislocation, their brains immediately removed, and the SVZ dissected. The SVZ tissue was digested by incubation in a mixture containing $0.1 \%$ papain (Worthington Biochemical) and $0.1 \%$ DNaseI (Roche) in Hank's buffered salt solution (Thermo Scientific) for $16 \mathrm{~min}$ at $37^{\circ} \mathrm{C}$. After brief trituration, $2 \mathrm{ml}$ of neurosphere growth medium was added and the cell suspension centrifuged at $250 \mathrm{~g}$ for $5 \mathrm{~min}$. The neurosphere growth medium consisted of mouse NeuroCult NSC basal medium containing mouse NeuroCult NSC proliferation supplements (Stem Cell Technologies), 2\% BSA (Invitrogen), $2 \mu \mathrm{g} / \mathrm{ml}$ heparin (Sigma), $20 \mathrm{ng} / \mathrm{ml}$ purified mouse receptor-grade epidermal-like growth factor (EGF; BD 
Biosciences), and $10 \mathrm{ng} / \mathrm{ml}$ recombinant bovine fibroblast growth factor-2 (FGF-2; Roche). The pellet was resuspended in another $2 \mathrm{ml}$ of neurosphere growth medium and mechanically triturated until smooth, to obtain a single-cell suspension. The cell preparation was then plated in neurosphere growth medium in a 24 well plate and cultured for a period of $7 \mathrm{~d}$ at $37^{\circ} \mathrm{C}$ in $5 \% \mathrm{CO}_{2}$.

To allow for differentiation, neurospheres were transferred to a 4 well slide coated with poly-D-lysine and L-orthonine and cultured in medium without the growth factors EGF and FGF-2 for a period of $5 \mathrm{~d}$ at $37^{\circ} \mathrm{C}$ in humidified $5 \% \mathrm{CO}_{2}$. On day 4 of differentiation, DT was added to half of the wells at $50 \mathrm{ng} / \mathrm{ml}$. Twenty-four hours later, the neurospheres were fixed and stained for DCX, as described above. The neurospheres were viewed on a Zeiss inverted fluorescence microscope, and the number of DCX-expressing cells in each neurosphere was quantified to obtain the percentage of neurospheres containing $<10,10-25$, or $>25$ DCXexpressing cells.

\section{Tissue processing and analysis}

Staining procedures. DCX staining was used to evaluate the number of immature neurons in the hippocampus, Arc and c-Fos staining was used to identify immediate early gene-expressing cells involved in memory consolidation (Shepherd and Bear, 2011), Ki-67 staining was used to examine the number of proliferating cells in the subgranular layer, and Iba1 and GFAP staining was used to identify microglia and astrocytes, respectively. For this, mice were deeply anesthetized with sodium pentobarbitone $(150 \mathrm{mg} / \mathrm{kg}$; Virbac) and transcardially perfused with $10 \mathrm{ml}$ of PBS, pH 7.5, followed by $30 \mathrm{ml}$ of $10 \%$ neutral buffered formalin, $\mathrm{pH} 7.5$. The brains were postfixed in formalin, cryoprotected in $30 \%$ sucrose, and sectioned at $40 \mu \mathrm{m}$ thickness using a sledge microtome. All staining was done on free-floating sections ( 1 in 6 series) through the entire hippocampus. Sections were washed three times for $10 \mathrm{~min}$ at RT and then incubated for $1 \mathrm{~h}$ in a blocking solution (1\% BSA, $0.2 \%$ Triton X-100 in PBS). Sections were then left overnight at $4^{\circ} \mathrm{C}$ immersed in diluent containing monoclonal rabbit anti-DCX (1:500; Abcam), guinea pig antiArc (1:500; Sysy), goat anti-c-Fos (1:500; Santa Cruz Biotechnology), rabbit anti-Ki-67 (1:1000; Abcam), rabbit anti-Ibal (1:500; Wako), or mouse anti-GFAP (1:500; Millipore) antibody. The following day, sections were washed and incubated for $1 \mathrm{~h}$ at RT with goat anti-rabbit AlexaFluor-488 (1:1000) or biotinylated anti-guinea pig IgG (1:1000; Vector Laboratories) followed by Cy3-streptavidin (1:1000). Sections were washed three times in PBS at RT (5 min per wash), then immediately mounted in Dako fluorescence mounting medium containing the nuclear stain DAPI (1:1000).

Double immunofluorescence staining was performed to determine the distribution of DTR in $D C X^{D T R}$ mice. For this immunolabeling, $D C X^{D T R}$ and WT mice were deeply anesthetized with sodium pentobarbitone, then transcardially perfused with $1 \%$ sodium nitrite in $0.1 \mathrm{M}$ PBS, $\mathrm{pH} 7.4$, followed by $4 \%$ paraformaldehyde, $14 \% \mathrm{v} / \mathrm{v}$ picric acid in $0.1 \mathrm{M}$ phosphate buffer. Brains were removed from the skull, hemisected, and postfixed via immersion in the same fixative for $2 \mathrm{~h}$ at RT. Tissues were washed three times in $0.1 \mathrm{M}$ PBS and processed into paraffin wax. Next, 10 $\mu \mathrm{m}$ coronal sections containing the hippocampus were cut and collected onto SuperFrost Plus slides (Menzel-Gläser). The paraffin wax was removed through immersion in $100 \%$ xylene, after which the sections were rehydrated through a graded series of ethanol and $\mathrm{H}_{2} \mathrm{O}$. Sections were incubated in an antigen recovery solution (Revealit-ag, ImmunoSolution) for $10 \mathrm{~min}$ at $85^{\circ} \mathrm{C}$ and washed three times in $0.1 \mathrm{M}$ PBS. Wells were created around sections using a Pap pen (Pro SciTech) before tissues were incubated in blocking solution for $30 \mathrm{~min}$. The sections were then incubated overnight in blocking solution containing the primary antibodies goat anti-HB-EGF (1:50; R\&D Systems) and rabbit anti-DCX (1:500; Abcam). Sections were washed and incubated for $5 \mathrm{~h}$ with biotinylated anti-goat IgG (1:500; Jackson Biosciences), then washed and incubated overnight in streptavidin-AlexaFluor-488 (1:1000, Invitrogen) and anti-rabbit IgG-AlexaFluor-647 (1:1000; Invitrogen). Finally, sections were washed three times in PBS at RT before being mounted in Dako fluorescence mounting medium. All incubations were performed at $4^{\circ} \mathrm{C}$ in a humidified chamber unless otherwise indicated. The specificity of
DTR staining was confirmed through omission of the primary antibody incubation step as well as the use of WT tissue.

Image analysis and quantification. Images were taken at $20 \times$ magnification using a Zeiss Axio Imager microscope and AxiocamMRm/3 camera together with AxioVision Software (Zeiss, Version 4.8.2). To determine the number of cells stained for DCX, Ki-67, Arc or c-Fos within each section, $Z$-stacks were taken at $1.75 \mu \mathrm{m}$ intervals throughout the entire $40 \mu \mathrm{m}$ section; quantitative counts were expressed as cells per unit length of dentate gyrus (Vukovic et al., 2012). Counts for Iba1- and GFAP-immunoreactive cells were performed using Stereo Investigator stereologic software. Using every sixth section throughout the rostrocaudal extent of the hippocampus, the total number of Iba1- and GFAPimmunoreactive cells was estimated by the optical fractionator method using a $40 \times$ plan-apo objective with a 1.4 numerical aperture. For every section analyzed, upper and lower "guard zones" of $5 \mu \mathrm{m}$ were established. The hippocampus was outlined under a objective and $\sim 20 \%$ of the outlined area was analyzed using a systematic random sampling design. The section thickness was measured every 5 counting frames, with each contour having $8-22$ evenly spaced counting frames, depending on the size of the contour. The counting frame was set at $500 \times 500$ pixels during analysis as this yielded a sufficiently low coefficient of error $(<0.1)$.

\section{Behavioral apparatus and procedures}

The active place avoidance task is a hippocampus-dependent spatial learning task (Cimadevilla et al., 2001; Wesierska et al., 2005). The apparatus (Bio-Signal Group) consisted of an elevated arena with a grid floor fenced with a $32-\mathrm{cm}$-high transparent circular boundary (enclosed arena diameter $77 \mathrm{~cm}$ ), located in a room with visual cues on the walls (see Fig. $2 A)$. The arena rotated counterclockwise $(0.75 \mathrm{rpm})$ and an electric shock could be delivered through the grid floor, which also rotated. The position of the animal in the arena was tracked using an overhead camera linked to Tracker software (Bio-Signal Group). During trials, a mouse was placed in the arena and trained to avoid a $60^{\circ}$ shock zone, the positioning of which was kept constant (i.e., did not rotate) in relation to the room coordinates; the mouse's "start" position was always near the wall on the side of the arena opposite the shock zone. Entrance into the shock zone led to the delivery of a brief foot shock $(500 \mathrm{~ms}, 60 \mathrm{~Hz}, 0.6 \mathrm{~mA})$. If, after the initial shock, the animal remained in the shock zone, further shocks were delivered at $1.5 \mathrm{~s}$ intervals until the animal moved out of the zone. Each training session lasted $10 \mathrm{~min}$ (habituation sessions were 5 min long), and recorded tracks were analyzed offline using Track Analysis software (Bio-Signal Group). Mice were habituated to the training environment $24 \mathrm{~h}$ before the initial experiment (i.e., a mouse was placed in the rotating arena with the shock turned off and allowed to explore the arena for $5 \mathrm{~min}$ ).

To test the role of adult neurogenesis at different stages of spatial learning and memory, we conducted three experiments using different cohorts of animals. Each experiment started with a habituation session, followed by a series of experimental blocks. Each block consisted of three $10 \mathrm{~min}$ training sessions per day. The position of the shock zone was kept constant with respect to the spatial frame of the room. To assess the extent of learning, the following parameters were measured: number of foot shocks delivered during a $10 \mathrm{~min}$ trial, maximal avoidance time, latency to first entry into the shock zone, and number of entries per distance covered (in meters).

The open field test (Harms et al., 2008) was used to assay the animals' locomotor activity. The open field tests were conducted using a square arena $(27.3 \times 27.3 \times 20.3 \mathrm{~cm})$ equipped with infrared beams $(\mathrm{Med}$ Associates). In each individual experiment, the mouse was placed in the center of the arena and the total distance traveled over 10 min was recorded, along with the number of entries into the central quadrant of the arena, rearings, and defecations.

The rotarod task was used to assay motor coordination, balance, and motor learning by measuring latency to the first fall from an accelerating rotating rod, with latencies averaged over multiple trials (Lalonde et al., 1995). The animal was placed on an accelerating rotating rod (acceleration 4-40 revolutions/min over $5 \mathrm{~min}$ ) and its motor function was measured as latency to the first fall. Each mouse was tested in two trials per day (10 min intertrial interval) for $2 \mathrm{~d}$. 
The hot-plate test was used to assess mouse pain sensitivity, as any differences in pain threshold between genotypes might affect avoidance learning (Bannon and Malmberg, 2007). An automated hot-plate (Harvard Instruments) was heated to $53^{\circ} \mathrm{C}$, each mouse was placed individually on the plate, and the latency of the mouse to lick its hindpaw was used as the measure of nociception (cutoff time $20 \mathrm{~s}$ ).

The elevated plus maze was used to obtain a measure of anxiety-related behavior (Carobrez and Bertoglio, 2005). The elevated plus maze was made from opaque gray acrylic and consisted of four opposing pairs of arms, two open $(5 \times 30 \mathrm{~cm})$ and two closed $(5 \times 30 \times 30 \mathrm{~cm})$, extending from a central platform $(5 \times 5 \mathrm{~cm})$ positioned $50 \mathrm{~cm}$ above the ground. Mice were placed on the central platform facing one of the open arms and allowed to freely explore the maze for $10 \mathrm{~min}$ while their behavior was videorecorded. The Ethovision 3.1 program (Noldus) was used for tracking and analysis. The distance mice moved in different arms of the maze was measured, as was the frequency of head-dipping, stretching, and rearing. The time that animals spent in the open arms of the maze, relative to the closed arms, was used as the primary measure of anxietyrelated behavior.

In all behavioral experiments, the floor and walls of the corresponding experimental apparatus were wiped with $70 \%$ ethanol after each trial. The experiments were conducted in such a way as to minimize bias in that WT and knock-in animals were tested in an alternating fashion. Three cohorts of mice were examined for general behavior between 1 and $3 \mathrm{~d}$ after the conclusion of DT treatment. One cohort was used for openfield and hot-plate testing, which took place one day after the last DT injection. The remaining two cohorts were used for testing rotarod and elevated plus maze performance at 1 and $3 \mathrm{~d}$ after the last DT injection, respectively.

\section{Data analysis}

Statistical analysis was performed using GraphPad Prism (GraphPad Software, Version 5.0c). Data were analyzed using an unpaired two-tailed Student's $t$ test or a repeated-measures two-way ANOVA with Bonferroni post hoc test, as appropriate. Values are expressed as mean \pm SEM with significance determined at $p<0.05$.

\section{Results \\ $D C X^{D T R}$ mice: a novel knock-in mouse model for the ablation of immature hippocampal neurons}

To examine the role of immature neurons in the hippocampus, we used genetic targeting to specifically ablate DCX-expressing $\left(\mathrm{DCX}^{+}\right)$cells. To do so, we generated a knock-in model ( $D C X^{D T R}$ mice), in which the human version of the receptor for DTR was constitutively expressed under the control of the DCX promoter. As such, all DCX ${ }^{+}$cells are primed to undergo apoptotic cell death once human DT has bound to the DTR. In the mouse, cells lacking DTR expression are insensitive to DTinduced cell death (Middlebrook and Dorland, 1977; Buch et al., 2005).

The efficacy of DT-induced $\mathrm{DCX}^{+}$cell depletion was first tested in vitro. Cortical cultures were established from P1 pups, as DCX protein is highly expressed by neurons during postnatal development, after which DT was added to the culture medium. The total number of $\mathrm{DCX}^{+}$cells was significantly reduced in cultures derived from heterozygous and homozygous $D C X^{D T R}$ mice in the presence of DT compared with WT mice (Fig. 1A). The loss of immature neurons was particularly pronounced in homozygous $D C X^{D T R}$ mice where no $\mathrm{DCX}^{+}$cells remained after DT treatment. Cultures derived from heterozygous $D C X^{D T R}$ mice showed an intermediate phenotype, whereas the number of $\mathrm{DCX}^{+}$cells in cultures derived from WT mice did not change in the presence of DT.

To further corroborate our findings, we performed additional in vitro experiments to test whether DT could also ablate $\mathrm{DCX}^{+}$ cells within differentiated neurospheres cultured from the adult
SVZ. Differentiation of neurospheres generated from this brain region results in the production of a large number of $\mathrm{DCX}^{+}$cells. Differentiated neurospheres from $D C X^{D T R}$ mice produced a similar number of $\mathrm{DCX}^{+}$cells to WT neurospheres in the absence of DT. However, exposure of these neurospheres to DT led to a marked decline in $\mathrm{DCX}^{+}$cells in preparations derived from homozygous $D C X^{D T R}$ mice (hereafter referred to as $D C X^{D T R}$ mice; Fig. $1 B$ ), with an overall shift toward neurospheres containing only a few immature neurons. In $D C X^{D T R}$ cultures, $\sim 10 \%$ of neurospheres contained $>25 \mathrm{DCX}^{+}$cells/neurosphere compared with $50 \%$ of WT neurospheres.

Having established that DT exposure was an effective means by which to induce loss of $\mathrm{DCX}^{+}$cells in vitro, we next assessed the efficacy of depletion in vivo. Both WT and $D C X^{D T R}$ mice were injected with DT every second day for $11 \mathrm{~d}$ (six injections in total). They were then killed on the day after the final injection, after which we assessed the number of $\mathrm{DCX}^{+}$cells present in the dentate gyrus. After DT injection, there was an $85 \%$ reduction in the number of $\mathrm{DCX}^{+}$cells in the $D C X^{D T R}$ dentate gyrus compared with the control region $(p<0.01$; Fig. $1 C, E, F)$. The number of proliferating $\mathrm{Ki}-67^{+}$cells was, however, similar between the genotypes (WT: $14 \pm 0.4$ cells/mm vs $D C X^{D T R}: 15 \pm 0.4$ cells $/ \mathrm{mm}$ ), as was the number of hippocampal neurospheres (data not shown). We also found no evidence of gliosis or microglial activation in $D C X^{D T R}$ mice as a result of DT treatment and the subsequent ablation of immature neurons (Fig. $1 G, H$ ). Specifically, there was no difference between genotypes in the number of $\mathrm{Iba}^{+}$microglia (WT: 74,443 $\pm 13,840$ cells, $n=4$, vs $D_{C X}{ }^{D T R}: 71,749 \pm 5758$ cells, $n=5$ ) or $\mathrm{GFAP}^{+}$astrocytes (WT: $120,108 \pm 13,133, n=3$, vs $\left.D C X^{D T R} 110,317 \pm 5635, n=5\right)$ in the hippocampus after DT injections. There was also no significant difference in the proportion of proliferating (i.e., BrdU ${ }^{+}$) microglia and astrocytes between genotypes (data not shown).

Staining for DTR was observed within the basal aspect of the granule cell layer of the $D C X^{D T R}$ dentate gyrus, where $\mathrm{DCX}^{+}$cells are located (Fig. 1I). Inspection at higher magnification showed a punctate, surface receptor-like staining pattern for DTR in close association with $\mathrm{DCX}^{+}$cells (Fig. $1 J$ ). No detectable levels of DTR staining were observed in other areas for which DCX expression has been reported, including the SVZ, rostral migratory stream, olfactory bulb, piriform cortex, hypothalamus, or amygdala (Fig. $1 \mathrm{~K}-\mathrm{O}$ ). A similarly restricted pattern of reporter gene expression was noted in the Rosa26-EYFP line when crossed with a transgenic mouse that expressed CreER ${ }^{\mathrm{T} 2}$ under control of the full-length $d c x$ promoter (Cheng et al., 2011), perhaps as a result of variations in DCX expression between different brain regions (Zhang et al., 2010).

Next, in a separate cohort of experimental mice, we quantified the number of DCX ${ }^{+}$cells present at 28 and $49 \mathrm{~d}$ after the last DT injection and observed that the population of $\mathrm{DCX}^{+}$cells in the $D C X^{D T R}$ mice had completely recovered at these time points (28 d: Fig. $1 D ; 49$ d: data not shown). Thus, the $D C X^{D T R}$ transgenic mouse represents a model in which $\mathrm{DCX}^{+}$immature hippocampal neurons can be specifically targeted and ablated.

\section{Ablation of immature hippocampal neurons results in learning deficits, which can be rescued after restoration of this population}

Having successfully established a transgenic mouse model that allows for in vivo ablation of immature neurons, we next aimed to evaluate the importance of these cells for hippocampal/dentate gyrus-dependent behavior by examining changes in learning and memory after $\mathrm{DCX}^{+}$cell ablation. Previous studies have drawn 
A

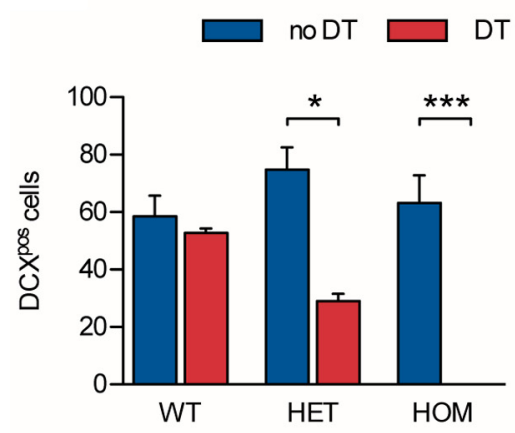

B

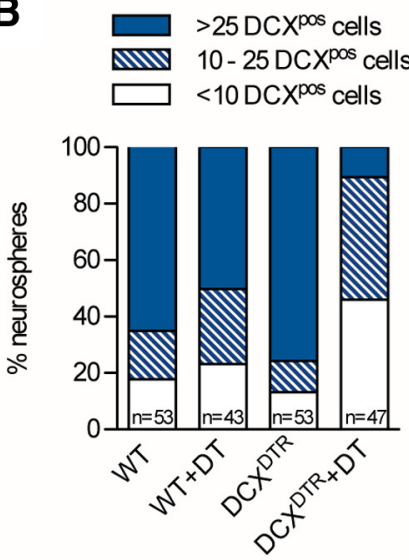

C

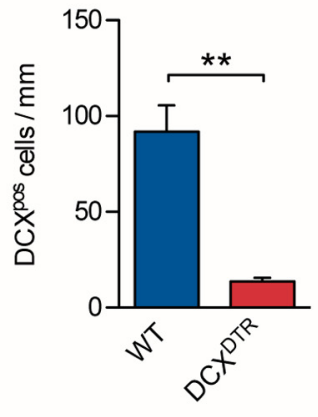

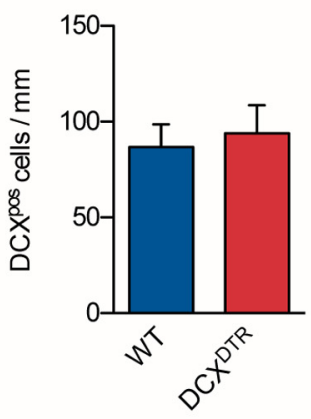
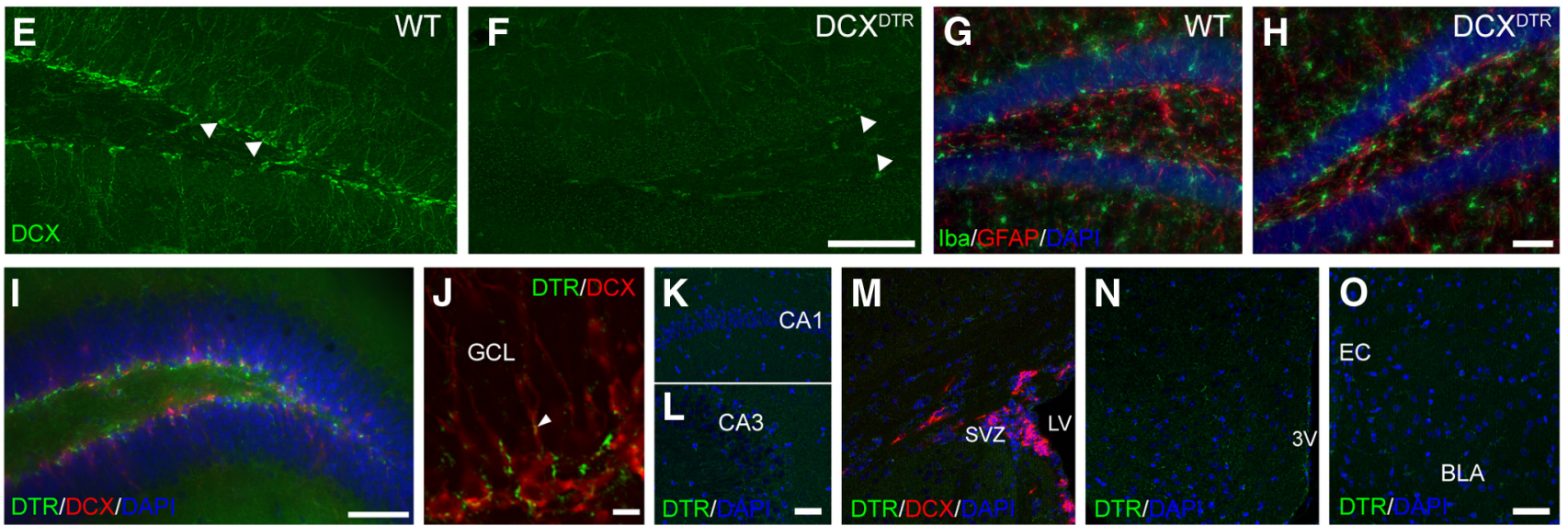

Figure 1. Depletion of immature neurons in $D C X^{D T R}$ knock-in mice. $A, D T$ ablated $D C X+$ cells in cultures of embryonic cortical neurons derived from heterozygous (HET; $n=3$ ) and homozygous $(\mathrm{HOM} ; n=4) D C X^{D T R}$ mice but not from WT controls $(n=2)$. $B$, Addition of DT to differentiated neurospheres ablated $D C X^{+}$cells. Note the dramatic reduction in the number of $D C X^{+}$cells encountered within neurospheres from $D C X^{D T R}$ mice after the addition of DT. $C$, In vivo DT administration resulted in depletion of $D C X^{+}$cells in the dentate gyrus of $D C X^{D T R}$ mice $(n=3)$ but not WT controls $(n=3)$. $\boldsymbol{D}$, Recovery of $D C X^{+}$cell numbers in the dentate gyrus in $D C X^{D T R}$ mice was observed $28 \mathrm{~d}$ after the last $D T$ injection $(n=4$ per condition). $\boldsymbol{E}, \boldsymbol{F}$, Representative images showing depletion of $D C X^{+}$cells in the dentate gyrus of $D C X^{D T R}$ but not WT mice after $D T$ treatment. White arrowheads indicate $D C X^{+}$cells. $G, H$, Representative images of the distribution of Iba ${ }^{+}$microglia and GFAP ${ }^{+}$astrocytes in WT and DCXTR mice after DT treatment. $I$, Photomicrograph showing staining for DTR (green) and DCX (red) in the dentate gyrus of $D C X^{D T R}$ mice (cell nuclei are counterstained blue with DAPI). $\boldsymbol{J}$, Higher-power image showing punctate DTR staining (green) in close association with DCX ${ }^{+}$cells (red) and their processes (white arrowhead). $\boldsymbol{K}-\mathbf{O}$, No detectable DTR staining was observed in other regions of the hippocampus (i.e., the CA1 and CA3) $(\boldsymbol{K}, \boldsymbol{L})$, the SVZ $(\boldsymbol{M})$, hypothalamus $(\boldsymbol{N})$, or amygdala (0). Scale bars: $\boldsymbol{E}, \boldsymbol{F}, 100 \mu \mathrm{m} ; \boldsymbol{I}, 70 \mu \mathrm{m} ; \boldsymbol{J}, 10 \mu \mathrm{m} ; \boldsymbol{K}-\mathbf{0}$, $50 \mu \mathrm{m} .{ }^{*} p<0.05 .{ }^{* *} p<0.01 .{ }^{* * *} p<0.001$. GCL, Granule cell layer; LV, lateral ventricle; $3 \mathrm{~V}$, third ventricle; BLA, basolateral amygdala; EC, external capsule.

links between impairments in hippocampal neurogenic processes and deficits in spatial learning using the Morris water maze (Dupret et al., 2008; Farioli-Vecchioli et al., 2008; Zhang et al., 2008), although the reported outcomes have been variable (Deng et al., 2010). Therefore, in this study, we aimed to test spatial learning in a more controlled fashion with a challenging version of the active place avoidance task. The apparatus used for this behavioral task, together with the visual cues displayed on the walls of the testing room, are schematically represented in Figure $2 A$. Experimental mice were placed on a turntable and tested for their ability to learn to avoid an unmarked shock zone using the distal visual cues present in the testing room as their reference. The readout from the active place avoidance task is depicted in Figure $2 B$. During the habituation phase of the test, experimental animals explored the arena randomly as indicated by the gray tracking path throughout the entire testing arena (Fig. 2B, top). After activation of the shock zone, animals normally learned to avoid this region, typically preferring to stay on the opposite side of the arena (Fig. $2 B$, bottom).

To test hippocampal-dependent learning in the absence of immature neurons, both $D C X^{D T R}$ and WT mice were treated with DT and subsequently tested in the active place avoidance task in "Room 1," $3 \mathrm{~d}$ after the last DT injection. The experimental design is shown in Figure $2 C$. In the 5 min habituation phase, during which the shock zone was not activated, both $D C X^{D T R}$ and WT mice explored the arena to a similar extent. The total distance covered (WT: $30.0 \pm 1.4 \mathrm{~m}$ vs $D C X^{D T R}: 26.7 \pm 1.5 \mathrm{~m}$ ), the number of "virtual shocks" (WT: $27.9 \pm 2.0$ vs $\left.D C X^{D T R}: 24.33 \pm 1.6\right)$, and the number of entries into the shock zone (WT: $13.3 \pm 0.8$ vs $\left.D C X^{D T R}: 12.1 \pm 1.0\right)$ were similar between genotypes $(n=12$ per experimental group). During habituation, the number of "virtual shocks" was typically higher than the number of entries into the shock zone because test animals were not presented with an aversive stimulus to encourage their exit from this area. However, after activation of the shock zone, the number of shocks received tended to equal the number of entries, as animals quickly escaped the aversive area. During test trials, $D C X^{D T R}$ mice had greater difficulty in avoiding the shock zone after DT treatment compared with their WT counterparts (Fig. 2D). DCX ${ }^{D T R}$ mice not only received significantly more shocks (Fig. $2 D$, left), they also avoided the shock zone for a reduced period of time (Fig. 2D, middle). The number of entries into the shock zone per distance covered (in meters) was also significantly greater for the $D C X^{D T R}$ cohort (Fig. 2D, right). These deficits in performance were partic- 
A

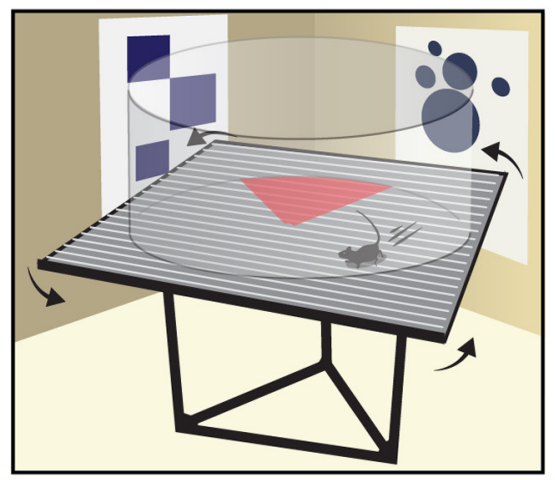

B

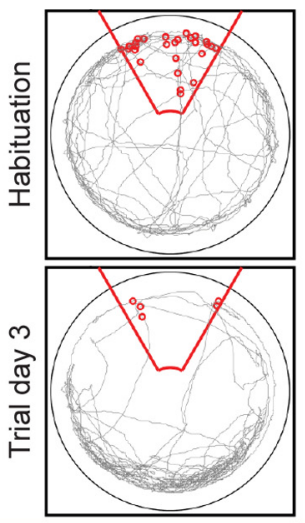

C



D
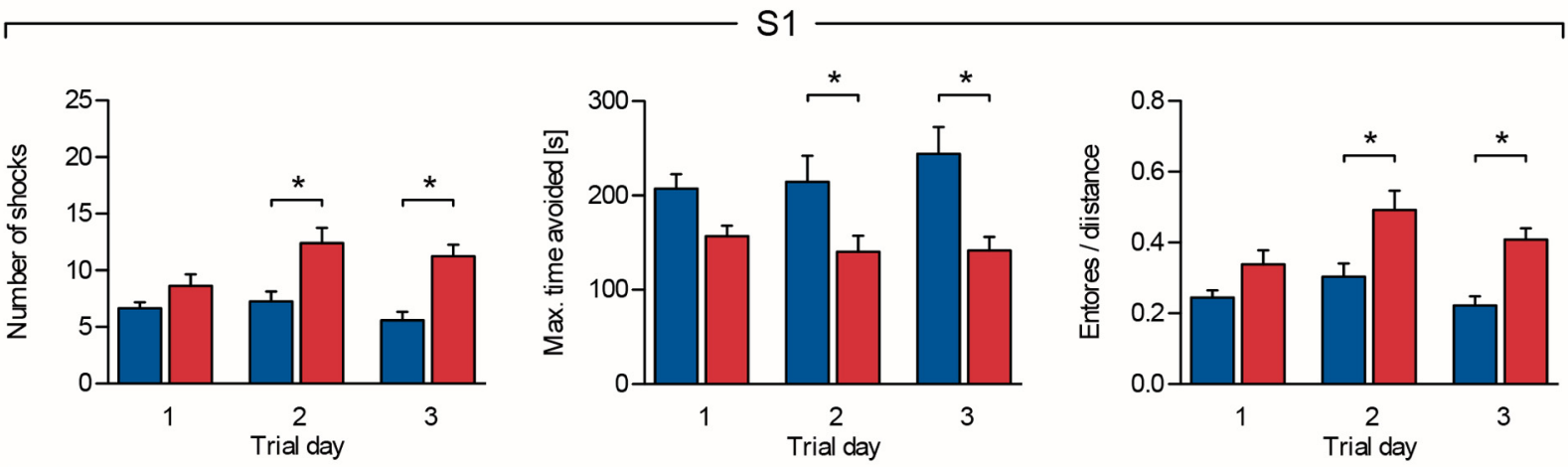

E

S2
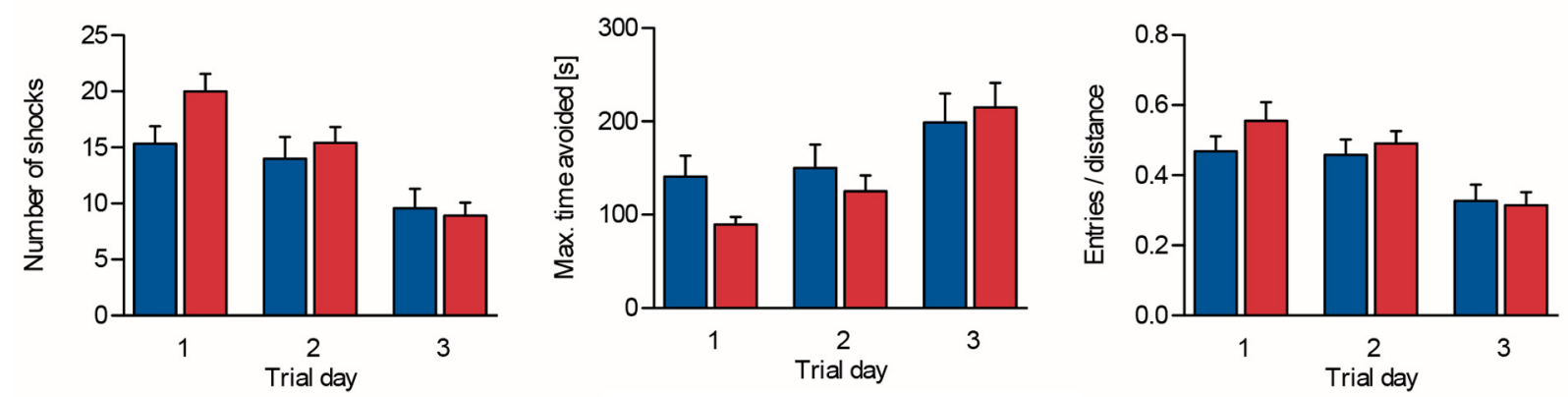

WT

$\square$ DCX DTR

Figure 2. Ablation of $D C X^{+}$cells impairs performance of the active place avoidance task; repopulation of $D C X^{+}$cells rescues acquisition of the task. $A$, Schematic representation of the active place avoidance task. Experimental mice were placed on top of a turntable, confined in a clear circular barrier. Using distal visual cues as a reference, the animals were trained to avoid a stationary shock zone (red triangle). $\boldsymbol{B}$, Depiction of the path tracked by the experimental mice (gray line) within the arena during habituation (top) and after trial day 3 of training (bottom). Red line indicates shock zone of $60^{\circ}$; small red circles represent "shocks" delivered. C, Experimental design used to assess the importance of DCX ${ }^{+}$cells for learning and memory in the active place avoidance task. $\boldsymbol{D}$, Acquisition of the active place avoidance task was significantly impaired in $D C X^{D T R}$ mice $3 \mathrm{~d}$ after $D T$ treatment. $D C X^{D T R}$ mice received more shocks than control mice $\left(\right.$ left: $\left.F_{(1,22)}=17.37, p<0.001\right)$, had shorter maximum shock zone avoidance time (middle: $F_{(1,22)}=12.81, p<0.01$ ), and had a higher number of entries into the shock zone per distance covered (right: $\left.F_{(1,22)}=15.06, p<0.001\right)$. $E$, At $45 \mathrm{~d}$ after ablation (i.e., after recovery of the $D C X^{+}$cell population), the $D C X^{D T R}$ mice performed as well as control animals in the new active place avoidance task. There was no difference observed in the number of shocks received $\left(F_{(1,22)}=1.23, p=0.28\right)$, maximum avoidance time $\left(F_{(1,22)}=0.76, p=0.39\right)$, or entries per distance $\left(F_{(1,22)}=0.56, p=0.46\right)$ between genotypes. $S$ indicates experimental session (i.e., S1, Session 1). ${ }^{* *} p<0.05$, Significance between genotypes for individual trial days (Bonferroni post hoc test). $n=12$ per experimental group.

ularly apparent on days 2 and 3 of the testing period. Several other parameters also reflected impaired performance of the $D C X^{D T R}$ mice in the active place avoidance task, with significant increases observed in the total number of entries into the shock zone (WT: $5.1 \pm 0.6$ vs $\left.D C X^{D T R}: 9.3 \pm 0.7 ; p<0.01\right)$ and time spent in the quadrant containing the shock zone (WT: $6.7 \pm 1.1 \mathrm{~s}$ vs $D C X^{D T R}$ $13.4 \pm 1.5 \mathrm{~s} ; p<0.001)$ on trial day 3 ( $n=12$ per genotype). In a separate cohort of mice, behavior was tested $17 \mathrm{~d}$ after DT treatment, revealing ongoing learning deficits. The number of shocks received here by $D C X^{D T R}$ mice was still significantly higher than that experienced by WT animals on both trial day 2 (WT: $5.5 \pm 1.3 \mathrm{vs} D C X^{D T R}$ : $10.75 \pm 2.1 ; p<0.05$ ) and trial day 3 (WT: $2.3 \pm 0.7$ vs $D C X^{D T R}$ : $8.0 \pm 0.9 ; p<0.05 ; n=4$ per genotype)

Having demonstrated the importance of $\mathrm{DCX}^{+}$immature neurons for learning and mastering a spatial task (Fig. 2D), we hypothesized that the behavioral deficits observed in the $D C X^{D T R}$ mice 
should be alleviated upon withdrawal of the DT treatment, which would allow for replenishment of the $\mathrm{DCX}^{+}$cell population. To investigate this, the same cohort of mice that was tested at $3 \mathrm{~d}$ after DT treatment (see above) and retested at $45 \mathrm{~d}$, but in a different room (Room 2) (Fig. 2E). This provided the animals with a novel environment and a new set of distal visual cues, thereby presenting them with a new active place avoidance learning task (Fig. 2C). This late time point, 8 weeks after the first DT injection, was selected based on a previous study, which reported that 6- to 8-week-old new neurons are preferentially recruited during new learning tasks (Kee et al., 2007). No significant differences were observed during Room 2 testing; both genotypes received a similar number of shocks on each trial day, avoided the shock zone for a similar period of time, and made the same number of entrances per distance into the shock area (Fig. 2E). Thus, the effects observed after DT-induced ablation of $\mathrm{DCX}^{+}$cells could be reversed once treatment ceased.

It should be noted that the relatively flat learning curve of the WT group in our initial experiments, resulting from very quick learning to avoid the shock sector during the first training trial (relative to the number of entries into this sector during habituation session; Fig. $2 D$ ), appears to be characteristic of the active place avoidance test and has also been reported by other research groups (Cimadevilla et al., 2001; Burghardt et al., 2012). In our experiment, this quick acquisition might have been further facilitated by running habituation on the rotating arena in the presence of the distal cues, thus allowing animals to preform a "spatial map" in advance of the first training trial session. In support of this, a clear trend toward a learning curve was observed during acquisition of the active avoidance task after a room change when habituation was omitted during the retesting (Fig. 2E). Two-way ANOVA confirmed improved performance during consecutive trials in this scenario, with mice receiving fewer shocks over time regardless of genotype $\left(F_{(2,22)}=20.64, p<0.0001\right)$. Similar results were obtained in later experiments during shock zone reversal (see below and Fig. 5, S3; Fig. 6, S4). These findings lend strong support to the notion that habituation allows experimental mice to partially construct a spatial memory, making it easier/faster for them to map the location of the shock sector during actual test trials. The overall greater number of shocks received by the control group during the second round of active place avoidance learning (Fig. 2E, S2) is likely to have resulted from a combination of experimental factors: (1) the lack of a habituation session before the start of training in Room 2 may have contributed to a slower pace of learning (and consequently more foot shocks being received); and (2) it must also be taken into consideration that these mice were already familiar with the active place avoidance task and therefore may have learned to associate the experimental rig with foot shocks. This may have made them more anxious upon reentering the arena, resulting in a greater number of entries into the shock zone. These possibilities are not mutually exclusive. As a very similar result was obtained during later experiments when test rooms were changed between training sessions 1 and 2 (see below and Fig. 6, S2), this profile appears to be a feature of the experimental paradigm rather than the result of irregular poor performance.

As changes in some types of behavior, such as altered motor activity or pain sensitivity, could affect performance in the active place avoidance test, we also conducted several additional tests using two separate cohorts of mice. One day after the last DT injection, we found behavior in the open field test to be unchanged between the WT and DCX ${ }^{D T R}$ animals, with no significant differences recorded in distance traveled, times the mouse reared onto its hind legs (Fig. $3 A, B$ ), or the number of entries
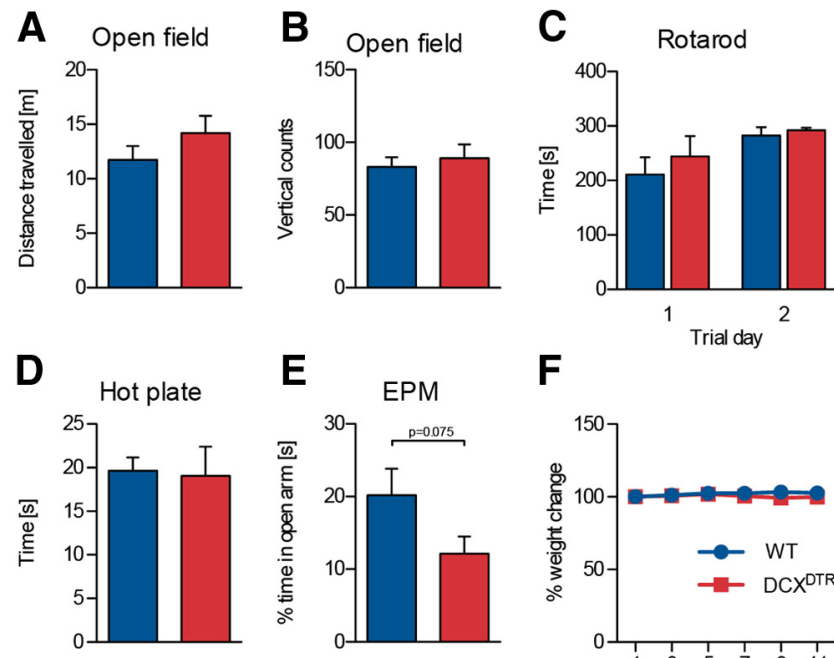

$\mathbf{F}$

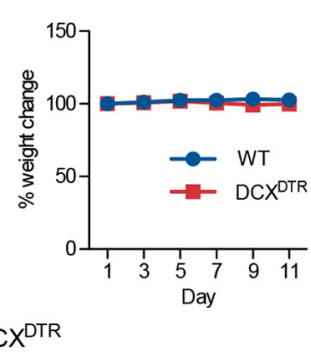

Figure 3. Depletion of $D C X^{+}$cells does not alter animals' performance in a range of general nonhippocampal-related tasks. $A, B, D$ T treatment did not affect behavior of experimental mice in the open field test. Similarly, motor performance on the accelerating rotarod $(\boldsymbol{C})$ and pain sensitivity, as assessed by the hot-plate test (D) (WT: $\left.n=6 ; D C X^{D T R}: n=5\right)$, were unaffected. $D C X^{D T R}$ mice appeared to spend less time in the open arms of an elevated plus maze (EPM) $(\boldsymbol{E})$, although this was not statistically significant (WT: $\left.n=9 ; D C X^{D T R}: n=11\right) . F$, DT administration did not negatively affect the body weight of experimental mice (WT: $\left.n=16 ; D C X^{D T R}: n=16\right)$.

into the center of the arena (WT: $129 \pm 8$ vs DCX ${ }^{D T R}: 143 \pm 15$; $p>0.05 ; n=4-6)$. Similarly, motor coordination, balance, and motor learning in the repeated rotarod test were not altered by DT-induced depletion of immature neurons (Fig. 3C). In addition, DT administration did not affect pain sensitivity as measured in the hot-plate test (Fig. $3 D$ ). $D C X^{D T R}$ mice did have a tendency to spend less time in the open arms in the elevated plus maze; however, this difference was not significant (Fig. 3E). Finally, as a measure of general health status, we closely monitored the animals' body weight during the DT treatment. Our treatment protocol of DT administration on alternating days (one injection every other day over $11 \mathrm{~d}$ ) did not induce any significant weight loss, and no difference in the percentage weight change was observed between $D C X^{D T R}$ and WT mice (Fig. $3 F$ ).

\section{Ablation of immature hippocampal neurons is associated with reduced expression of immediate early genes}

It was noted during the initial characterization of the $D C X^{D T R}$ line that DT treatment reduced the number of Arc-positive cells in the dentate gyrus (WT: $16.6 \pm 1.3$ cells/mm vs $D C X^{D T R}: 10.3 \pm$ 0.4 cells $/ \mathrm{mm}, n=3$ per genotype; $p<0.01$ ). The vast majority of these $\mathrm{Arc}^{+}$cells were observed within the granule cell layer, which typically contains more mature neurons. Consistent with this finding, only a very small percentage $(<1.5 \%)$ of immature $\mathrm{DCX}^{+}$neurons cells were found to express Arc. Nonetheless, the number of Arc-expressing DCX ${ }^{+}$cells was also significantly reduced in the $D C X^{D T R}$ mice (WT: $0.5 \pm 0.05$ cells $/ \mathrm{mm}, n=4$, vs $D C X^{D T R}: 0.2 \pm 0.03$ cells $\left./ \mathrm{mm}, n=5 ; p<0.01\right)$.

As Arc is an immediate early gene thought to be involved in memory consolidation (Shepherd and Bear, 2011), we next examined its expression in relation to learning and subsequent recovery of the $\mathrm{DCX}^{+}$cell population. To assess Arc expression during learning, additional cohorts of WT and $D C X^{D T R}$ mice were treated with DT and trained in the active place task for $2 \mathrm{~d}$, as per our previous experiments. On day 3 , the shock zone was 

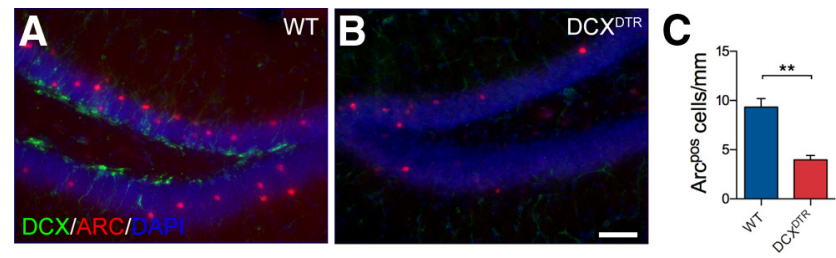

Figure 4. Arcexpression is reduced in $D C X^{D T R}$ mice during learning. $A, B$, Representative images of Arc (red) and DCX (green) expression in DCX ${ }^{D T R}$ mice, compared with WT mice, during learning (cell nuclei are counterstained blue with DAPI). C, Quantification of Arc ${ }^{+}$cells after active place avoidance learning revealed that the overall number of cells expressing Arc was significantly reduced in $D C X^{D T R}$ mice. Asterisks indicate significance between genotypes as determined by Student's $t$ test. ${ }^{* *} p<$ $0.01\left(\mathrm{WT}: n=4 ; D C X^{D T R}: n=4\right)$. Scale bars: $A, B, 50 \mu \mathrm{m}$.

deactivated to avoid the possibility that the induction of Arc expression could have arisen, at least in part, from the delivery of electric shocks rather than learning. Animals were then allowed to navigate the rig for $3 \mathrm{~min}$ before being perfused within $60 \mathrm{~min}$. Consistent with our initial observations, the overall number of Arc-expressing cells under this experimental paradigm was significantly reduced in $D C X^{D T R}$ mice (WT: $9.3 \pm 0.9$ cells $/ \mathrm{mm}$; vs $D C X^{D T R}: 4.0 \pm 0.5$ cells $/ \mathrm{mm}, n=4$ per genotype; $p<0.01$; Fig. $4 A-C)$. The number of cells expressing c-Fos, another immediate early gene activated by a variety of stimuli, was not different between genotypes (WT: $224 \pm 21$ vs $D C X^{D T R} 199 \pm 26$ cells per dentate gyrus, $n=4$ per genotype; $p=0.5$ ). When specifically examining Arc expression in immature neurons, we found a significant increase in the number of $\mathrm{DCX}^{+} \mathrm{Arc}^{+}$cells in WT mice after active avoidance learning compared with their naive counterparts (i.e., WT mice that had been treated with DT but were not exposed to the experimental rig) (WT: $0.2 \pm 0.04$ cells $/ \mathrm{mm}$ vs WT naive: $0.1 \pm 0.01$ cells $/ \mathrm{mm}, n=4$ per genotype; $p<0.05$ ). Virtually no Arc-expressing $\mathrm{DCX}^{+}$cells were observed in the $D C X^{D T R}$ mice because of the DT-induced ablation of immature neurons (WT: $0.2 \pm 0.04$ cells $/ \mathrm{mm}$ vs $D C X^{D T R}: 0.01 \pm 0.01$ cells/ $\mathrm{mm}, n=4$ per genotype; $p<0.01)$. If, however, $D C X^{D T R}$ mice were allowed to recover from DT treatment for 8 weeks, thereby allowing immature neurons to repopulate the dentate gyrus before being exposed to the active place avoidance task and subsequently killed $24 \mathrm{~h}$ later, the number of Arc-expressing DCX ${ }^{+}$cells was not different between genotypes (WT: $0.1 \pm 0.02$ cells, $n=5$, vs $D C X^{D T R}: 0.1 \pm 0.02$ cells, $\left.n=4\right)$. Overall, these data suggest a tight relationship between expression of the immediate early gene Arc in immature neurons and behavioral performance.

\section{Immature neurons are not required for recall of a familiar spatial task}

Having illustrated the importance of $\mathrm{DCX}^{+}$immature neurons for mastering a novel and challenging spatial task, we next tested the premise that retrieval of a learned memory in relation to the now familiar task may also require the presence of such cells (experimental design, Fig. 5A). For this, new cohorts of naive mice were tested in the active place avoidance task. In the absence of DT treatment, $D C X^{D T R}$ and WT mice exhibited no significant differences in any of the parameters measured, confirming that genomic insertion of the $D C X^{D T R}$ construct (in the absence of DT treatment) had no effect on the animals' performance. Without DT treatment, $D C X^{D T R}$ and WT animals received a similar number of shocks (Fig. 5B). No significant differences were observed between genotypes in, for example, the "maximal time of avoidance” (WT: $246 \pm 31 \mathrm{~s}, n=11$, vs DCX ${ }^{D T R}: 307 \pm 46 \mathrm{~s}, n=9$ ) or the "number of entries per distance" (WT: $0.19 \pm 0.04, n=11$, vs $D C X^{D T R}: 0.20 \pm 0.04, n=9$ ) on trial day 3 (when differences would have otherwise been present with DT treatment). Next, the animals were treated with DT and retested under the same conditions (i.e., unaltered visual cues or positioning of the entry and shock zones). Again, no significant differences in behavior were observed between genotypes (Fig. 5C). These results suggest that the lack of an immature neuron population in the hippocampus did not impact on performance in the familiar spatial task, as both $D C X^{D T R}$ and WT mice learned to avoid the shock zone with similar success. To further corroborate our finding that immature neurons are particularly important for mastering a novel spatial task, the animals were retested, but with altered visual cues and position of the shock zone. Under these circumstances, $D C X^{D T R}$ mice were unable to master the novel spatial task as well as WT mice, receiving significantly more shocks on trial day 3 (Fig. 5D). Together, these findings suggest that an intact population of $\mathrm{DCX}^{+}$immature neurons is critical for mastering a novel spatial task, but that these cells are redundant for memory retrieval in a familiar spatial task.

\section{Repeated ablation of immature neurons induces spatial learning deficits}

Finally, we tested whether impairments in learning a spatial task could be repeatedly induced in the same cohort of mice by exposing the animals to another round of DT treatment 8 weeks after administration of the first round of DT. A schematic overview of the experimental design is shown in Figure 6A. In brief, mice were tested in the active place avoidance task after the initial ablation of $\mathrm{DCX}^{+}$cells, after recovery of the $\mathrm{DCX}^{+}$cell population upon cessation of round 1 of DT treatment and directly after the second round of DT-induced $\mathrm{DCX}^{+}$cell ablation. Mice were retested in both the familiar task (session 3 ) and a novel configuration (session 4) in which the position of the shock and entry zones was reversed but the spatial cues remained the same. In line with our previous findings, $D C X^{D T R}$ mice received a greater number of shocks when tested in the active place avoidance task after initial depletion of the immature neurons (Fig. 6B). This deficit in the ability to rapidly master a challenging spatial learning task was again rescued after a rest period (to allow replenishment of $\mathrm{DCX}^{+}$population), as no difference was observed in the number of shocks received by mice of either genotype at 8 weeks after DT treatment (Fig. 6C). In line with our previous observations, the second depletion did not induce a significant performance deficit when animals were retested in the already familiar task (Fig. 6D). However, when presented with reversal of the location of the shock and entry zones, $D C X^{D T R}$ mice received significantly more shocks during trial day 1 , although on trial days 2 and 3 a similar number of shocks was delivered to $D C X^{D T R}$ and WT mice (Fig. $6 E)$. Thus, repeated depletion of immature neurons in the $D C X^{D T R}$ transgenic mouse model significantly slowed reversal learning in the active place avoidance task, suggesting a negative effect on cognitive flexibility.

\section{Discussion}

To define the significance of adult-born immature hippocampal neurons, we generated a knock-in mouse model that allowed for effective and targeted depletion of $\mathrm{DCX}^{+}$cells. It has been proposed that the unique properties of immature neurons (e.g., increased excitability) underpin some types of learning (Ge et al., 2007). To date, however, this hypothesis has not been tested genetically through their specific depletion. Previous studies have mostly disrupted neurogenesis at an early stage by preventing proliferation of neural precursor cells through irradiation, antimitotic agents, or, more recently, transgenic approaches target- 
A

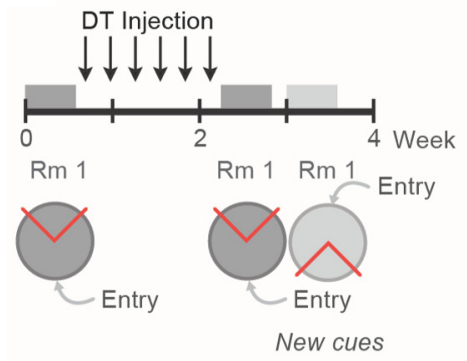

S1
B

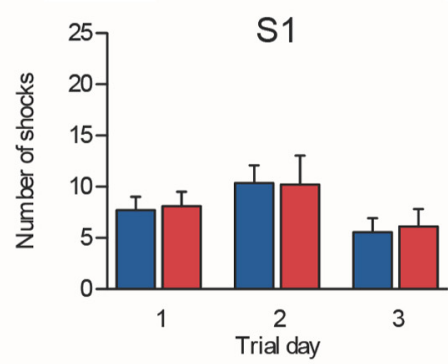

C

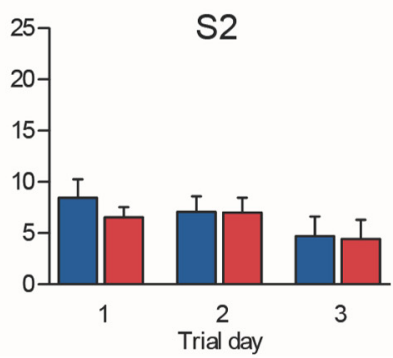

D

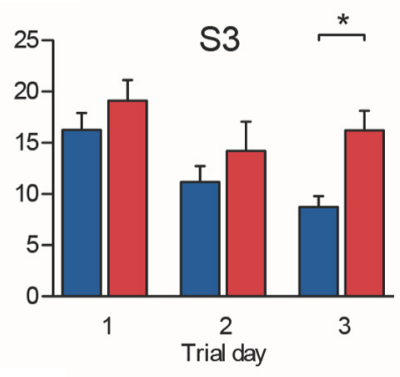

Figure 5. Immature $D C X^{+}$neurons are not important for recall of a previously learned task but are important for learning new hippocampal-dependent tasks. $A$, Experimental design used to assess recall of the already learned task after DT treatment, as well as learning of a new task where the cues and entry point have been altered. $\boldsymbol{B}$, There was no difference in the number of shocks delivered during the initial learning period in the active place avoidance task $\left(F_{(1,18)}=0.02, p=0.88\right)$. C. When retested after $D C X^{+}$cell ablation, $D C X^{D T R}$ mice performed equally as well as controls $\left(F_{(1.18)}=0.16, p=0.70\right)$. D, Changing the distal visual cues and shock/entry zone positions precipitated a deficit in $D C X$-ablated animals, which showed impaired acquisition of this new task as evidenced by a significant increase in the number of shocks received by this group on day 3 of the new training protocol $\left(F_{(1,18)}=4.51, p<0.05\right)$. S indicates experimental session (i.e., $S 1$, Session 1). ${ }^{*} p<0.05$, significance between genotypes for individual trial days (Bonferroni post hoc test). WT: $n=11 ; D C X^{D T R}: n=9$.

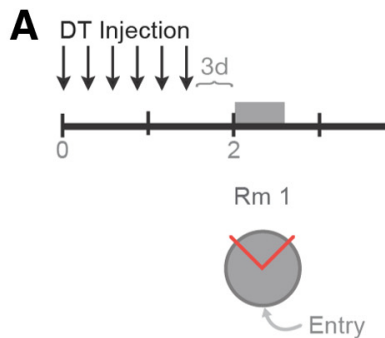

S1

\section{C}

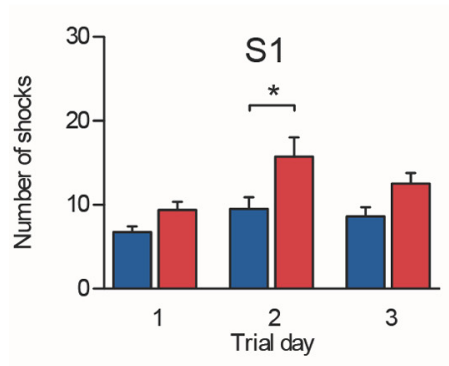

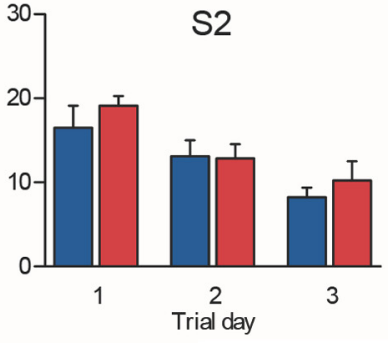

D

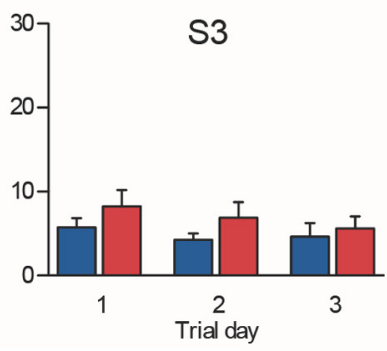

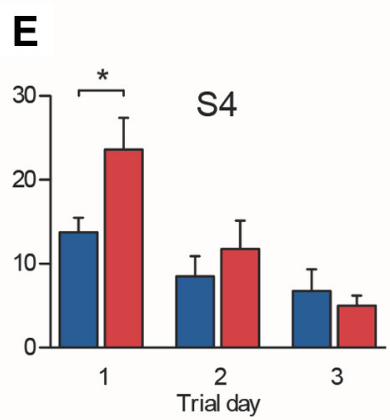

WT

DCXDTR

Figure 6. Repeated depletion of immature neurons in the $D C X^{D T R}$ transgenic mouse model impairs reversal learning in the active place avoidance task. $A$, Experimental design used to test acquisition deficits $(S 1)$, recovery $(S 2)$, recall $(S 3)$, and reversal learning $(S 4)$ after multiple rounds of $D T$-induced $D C X^{+}$cell ablation. $B, D C X^{D T R}$ mice received a greater number of shocks when tested in the active place avoidance task after initial depletion of the immature neurons $\left(F_{(1,14)}=11.28, p<0.01\right)$. C. This deficit was rescued after a rest period during which time the immature neurons repopulated the dentate gyrus in either genotype $\left(F_{(1,14)}=0.68, p=0.42\right)$. $\boldsymbol{D}$, The second depletion did not produce a deficit when animals were retested in the already familiar task $\left(F_{(1,14)}=1.70, p=0.21\right) . \boldsymbol{E}$, When presented with a reversal of location of the shock and entry zones, $D C X^{D T R}$ mice were slower than WT mice in adjusting their behavior to avoid the shock zone, with two-way ANOVA showing an interaction between genotype and time $\left(F_{(2,14)}=3.28, p=0.05\right)$. Sindicates experimental session (i.e., S1, Session 1). ${ }^{*} p<0.05$, Significance between genotypes for individual trial days (Bonferroni post hoc test). $n=8$ per experimental group.

ing Nestin-expressing and/or GFAP-expressing cells (ArrudaCarvalho et al., 2011; Snyder et al., 2011). These approaches result in sustained impairment in production of both immature neurons (including $\mathrm{DCX}^{+}$cells) and other cell types arising from the neural cell precursor pool, exerting a depletion effect for prolonged periods of time. Using DTR expression under endogenous DCX promoter control, we were able to selectively target immature neurons, as DCX has been shown to colocalize with early neuronal markers, such as $\beta$ III-tubulin and Map2 but not neural precursor/ stem cell markers, including Nestin and GFAP (Karl et al., 2005). This approach thereby allowed us to transiently deplete immature $\left(\mathrm{DCX}^{+}\right)$neurons after only a relatively short treatment with DT (6 injections over $11 \mathrm{~d}$ ), and to also repeatedly examine the contribution of immature neurons to different stages of learning and memory through multiple rounds of depletion.

\section{Immature neurons are important for acquisition of spatial learning}

Ablation of immature neurons caused deficits in the acquisition of the active place avoidance task for up to at least $17 \mathrm{~d}$ after cessation of DT treatment (i.e., $28 \mathrm{~d}$ after the first injection). Typically, no significant difference in acquisition was observed between $D C X^{D T R}$ and WT animals on trial day 1 . However, difficulty in learning consolidation became readily apparent in ani- 
mals deficient in immature neurons on trial days 2 and 3. The majority of previous studies using a classical spatial task, the Morris water maze, observed no such deficits in acquisition, with impaired performance only becoming apparent during probe trials (Saxe et al., 2006; Zhang et al., 2008; Deng et al., 2009; ArrudaCarvalho et al., 2011). In comparison with the water maze, the active place avoidance task adds extra complexity by requiring the animal to be constantly aware of its changing location in relation to the shock zone because of the continuous rotation of the apparatus. As such, the animal has to detect subtle changes in movement and the location of spatial cues to navigate optimally. One could therefore hypothesize that the task requires a similar level of hippocampal processing to the one present during pattern separation tasks in which the ability of animals to discriminate between minimal changes in the environment is tested. Our findings therefore accord with those of several recent studies reporting deficits in pattern separation after ablation of neurogenesis (Clelland et al., 2009; Sahay et al., 2011; Tronel et al., 2011; Kheirbek et al., 2012; Nakashiba et al., 2012). Nonetheless, it must be noted that, in their recent study, Burghardt et al. (2012) did not observe a deficit in acquisition of the active place avoidance task when neurogenesis was impaired through ablation of neural precursors. However, the active place avoidance task in this study was conducted by administering multiple trials per day, with intertrial intervals allowing for robust acquisition of the task. In our study, animals were only tested once per day, but over $3 \mathrm{~d}$, aiming for more gradual learning with an increased requirement for efficient long-term consolidation of the memory trace between training days. We think that this is a critical difference that allowed us to expose differences in learning after depletion of immature neurons. Similarly, different outcomes have been observed for contextual fear conditioning, where the behavioral significance of neurogenesis was illustrated when a single shock was paired with a context, but not with multiple shock pairings (Drew et al., 2010). Considering that neurogenesis appears to be involved in the consolidation of subtle but critical information, the level of difficulty of the task should therefore be a major factor for consideration when seeking to detect behavioral deficits under conditions where neurogenesis is impaired.

Our depletion strategy also provided us with a unique opportunity to examine whether the observed behavioral deficits could be reversed after withdrawal of DT treatment, thereby allowing the rapid replenishment of immature neurons from the unaffected neural precursor pool. The acquisition phenotype in the active place avoidance task indeed disappeared after recovery of the $\mathrm{DCX}^{+}$cell population, thereby conclusively demonstrating its importance for learning. These findings also illustrate the robustness of the adult neurogenic niche, particularly its ability to successfully reconstitute a fully functional population of immature neurons. The only other study to show recovery of normal behavior after transient blockade of neurogenesis was performed by Deng et al. (2009), whose findings suggest that the presence of immature neurons ( $\sim 4$ weeks of age) is important for reducing extinction of learned spatial preference in the Morris water maze task. To our knowledge, the present study is the first to report recovery from acquisition deficits.

In our model, learning deficits remained present for up to at least $17 \mathrm{~d}$ after DT treatment, indicating that $\mathrm{DCX}^{+}$cells must be at least $\sim 3$ weeks of age before they can make a significant contribution to spatial learning in the active place avoidance task. Such a finding is in line with previous studies showing that the initial synaptic connections of adult-born neurons with afferent connections from the entorhinal cortex are only established at day 16 (Zhao et al., 2006; Toni et al., 2008). Expression of immediate early genes, which are important for synaptic plasticity and thus learning (Lanahan and Worley, 1998; Shepherd and Bear, 2011), also appears to peak 3 weeks after the birth of immature neurons (Jessberger and Kempermann, 2003; Kee et al., 2007; Snyder et al., 2009), and these cells are thought to become preferentially recruited during learning from 4 weeks of age (Kee et al., 2007). In the present study, we observed that a reduction in the number of $\mathrm{DCX}^{+}$cells also led to a profound decrease in Arc expression, suggesting an important role for immature neurons in regulating overall synaptic plasticity within the dentate gyrus during learning.

\section{Immature $\mathrm{DCX}^{+}$neurons are not important for memory recall in a spatial task}

We also examined whether the presence of $\mathrm{DCX}^{+}$cells was required for remembering an already familiar (i.e., learned) task. In our study, we observed no behavioral recall deficits if $\mathrm{DCX}^{+}$cells were ablated after acquisition of the active place avoidance task, suggesting that this pool of immature neurons was not important for recalling a familiar task. These findings appear somewhat at odds with two recent reports stating that adult-born neurons are required for memory recall (Arruda-Carvalho et al., 2011; Gu et al., 2012). Although the initial study by Arruda-Carvalho et al. (2011) used a DT-based depletion strategy that ablated adultborn neurons up to $\sim 16$ weeks of age, the more recent paper by $\mathrm{Gu}$ et al. (2012) used elegant optogenetic approaches to demonstrate that integration of a cohort of $\sim 4$ week-old cells appears particularly important for hippocampal memory retrieval. As the DCX protein is only highly expressed up to 3 weeks after the birth of neurons (Snyder et al., 2009), a likely explanation for the differences between our studies is therefore that the $D C X^{D T R}$ mouse model depletes adult-born neurons before their integration, with the majority of these cells simply being too young to commit to a memory trace and play a role in recall. It is therefore important to note that our findings do not preclude a role for adult-born neurons in the recall of a spatial memory once these cells have sufficiently matured and integrated into the existing neural circuitry at $\sim 4$ weeks of age. Rather, they show that young immature neurons in the $\mathrm{DCX}^{+}$cell population do not yet have such a role, at least not in the active place avoidance task. Future experiments should reveal whether a more similar spatial learning task and timing of the recall can further reconcile the differences between previous studies and the present findings.

In our final experimental protocol, we induced a second round of depletion of $\mathrm{DCX}^{+}$cells in a cohort of animals that had recovered from the first episode, again confirming that immature neurons were not required to remember the already familiar active place avoidance task. However, behavioral deficits again became apparent for $D C X^{D T R}$ mice when we tested reversal learning (i.e., changing the shock zone location). The reversal task tests cognitive flexibility, as an animal needs to learn to suppress some aspects of the previously learned response, transfer some of the other aspects, and simultaneously learn new spatial locations to adapt to the changed circumstances and complete the task successfully. This type of task highlights deficits in mice with reduced neurogenesis (Garthe et al., 2009; Burghardt et al., 2012).

In conclusion, although adult-born immature neurons are important for learning a spatial task, they appear redundant in remembering a learned task. These findings have importance for our understanding of conditions that affect memory formation and demonstrate the potential of stimulating neurogenesis as a means of alleviating learning deficits. 


\section{References}

Arruda-Carvalho M, Sakaguchi M, Akers KG, Josselyn SA, Frankland PW (2011) Posttraining ablation of adult-generated neurons degrades previously acquired memories. J Neurosci 31:15113-15127. CrossRef Medline

Bannon AW, Malmberg AB (2007) Models of nociception: hot-plate, tailflick, and formalin tests in rodents. Curr Protoc Neurosci 8:Unit 8.9. CrossRef Medline

Buch T, Heppner FL, Tertilt C, Heinen TJ, Kremer M, Wunderlich FT, Jung S, Waisman A (2005) A Cre-inducible diphtheria toxin receptor mediates cell lineage ablation after toxin administration. Nat Methods 2:419-426. CrossRef Medline

Burghardt NS, Park EH, Hen R, Fenton AA (2012) Adult-born hippocampal neurons promote cognitive flexibility in mice. Hippocampus 22: 1795-1808. CrossRef Medline

Carobrez AP, Bertoglio LJ (2005) Ethological and temporal analyses of anxiety-like behavior: the elevated plus-maze model 20 years on. Neurosci Biobehav Rev 29:1193-1205. CrossRef Medline

Cheng X, Li Y, Huang Y, Feng X, Feng G, Xiong ZQ (2011) Pulse labeling and long-term tracing of newborn neurons in the adult subgranular zone. Cell Res 21:338-349. CrossRef Medline

Cimadevilla JM, Wesierska M, Fenton AA, Bures J (2001) Inactivating one hippocampus impairs avoidance of a stable room-defined place during dissociation of arena cues from room cues by rotation of the arena. Proc Natl Acad Sci U S A 98:3531-3536. CrossRef Medline

Clelland CD, Choi M, Romberg C, Clemenson GD Jr, Fragniere A, Tyers P, Jessberger S, Saksida LM, Barker RA, Gage FH, Bussey TJ (2009) A functional role for adult hippocampal neurogenesis in spatial pattern separation. Science 325:210-213. CrossRef Medline

Deng W, Saxe MD, Gallina IS, Gage FH (2009) Adult-born hippocampal dentate granule cells undergoing maturation modulate learning and memory in the brain. J Neurosci 29:13532-13542. CrossRef Medline

Deng W, Aimone JB, Gage FH (2010) New neurons and new memories: how does adult hippocampal neurogenesis affect learning and memory? Nat Rev Neurosci 11:339-350. CrossRef Medline

Drew MR, Denny CA, Hen R (2010) Arrest of adult hippocampal neurogenesis in mice impairs single- but not multiple-trial contextual fear conditioning. Behav Neurosci 124:446-454. CrossRef Medline

Dupret D, Revest JM, Koehl M, Ichas F, De Giorgi F, Costet P, Abrous DN, Piazza PV (2008) Spatial relational memory requires hippocampal adult neurogenesis. PLoS One 3:e1959. CrossRef Medline

Farioli-Vecchioli S, Saraulli D, Costanzi M, Pacioni S, Cinà I, Aceti M, Micheli L, Bacci A, Cestari V, Tirone F (2008) The timing of differentiation of adult hippocampal neurons is crucial for spatial memory. PLoS Biol 6:e246. CrossRef Medline

Garthe A, Behr J, Kempermann G (2009) Adult-generated hippocampal neurons allow the flexible use of spatially precise learning strategies. PLoS One 4:e5464. CrossRef Medline

Ge S, Yang CH, Hsu KS, Ming GL, Song H (2007) A critical period for enhanced synaptic plasticity in newly generated neurons of the adult brain. Neuron 54:559-566. CrossRef Medline

Goodman T, Trouche S, Massou I, Verret L, Zerwas M, Roullet P, Rampon C (2010) Young hippocampal neurons are critical for recent and remote spatial memory in adult mice. Neuroscience 171:769-778. CrossRef Medline

Gu Y, Arruda-Carvalho M, Wang J, Janoschka SR, Josselyn SA, Frankland PW, Ge Shaoyu (2012) Optical controlling reveals time-dependent roles for adult-born dentate granule cells. Nat Neuorsci 15:1700-1706. CrossRef Medline

Harms LR, Eyles DW, McGrath JJ, Mackay-Sim A, Burne TH (2008) Developmental vitamin D deficiency alters adult behaviour in 129/SvJ and C57BL/6J mice. Behav Brain Res 187:343-350. CrossRef Medline

Jessberger S, Kempermann G (2003) Adult-born hippocampal neurons mature into activity-dependent responsiveness. Eur J Neurosci 18:2707-2712. CrossRef Medline

Karl C, Couillard-Despres S, Prang P, Munding M, Kilb W, Brigadski T, Plötz S, Mages W, Luhmann H, Winkler J, Bogdahn U, Aigner L (2005) Neuronal precursor-specific activity of a human doublecortin regulatory sequence. J Neurochem 92:264-282. CrossRef Medline

Kee N, Teixeira CM, Wang AH, Frankland PW (2007) Preferential incorporation of adult-generated granule cells into spatial memory networks in the dentate gyrus. Nat Neurosci 10:355-362. CrossRef Medline

Kheirbek MA, Tannenholz L, Hen R (2012) NR2B-dependent plasticity of adult-born granule cells is necessary for context discrimination. J Neurosci 32:8696-8702. CrossRef Medline

Kubík S, Fenton AA (2005) Behavioral evidence that segregation and representation are dissociable hippocampal functions. J Neurosci 25 : 9205-9212. CrossRef Medline

Lalonde R, Bensoula AN, Filali M (1995) Rotorod sensorimotor learning in cerebellar mutant mice. Neurosci Res 22:423-426. CrossRef Medline

Lanahan A, Worley P (1998) Immediate-early genes and synaptic function. Neurobiol Learn Mem 70:37-43. CrossRef Medline

Middlebrook JL, Dorland RB (1977) Response of cultured mammalian cells to the exotoxins of Pseudomonas aeruginosa and Corynebacterium diphtheriae: differential cytotoxicity. Can J Microbiol 23:183-189. CrossRef Medline

Nakashiba T, Cushman JD, Pelkey KA, Renaudineau S, Buhl DL, McHugh TJ, Rodriguez Barrera V, Chittajallu R, Iwamoto KS, McBain CJ, Fanselow MS, Tonegawa S (2012) Young dentate granule cells mediate pattern separation, whereas old granule cells facilitate pattern completion. Cell 149:188-201. CrossRef Medline

Sahay A, Scobie KN, Hill AS, O'Carroll CM, Kheirbek MA, Burghardt NS, Fenton AA, Dranovsky A, Hen R (2011) Increasing adult hippocampal neurogenesis is sufficient to improve pattern separation. Nature 472:466-470. CrossRef Medline

Saxe MD, Battaglia F, Wang JW, Malleret G, David DJ, Monckton JE, Garcia AD, Sofroniew MV, Kandel ER, Santarelli L, Hen R, Drew MR (2006) Ablation of hippocampal neurogenesis impairs contextual fear conditioning and synaptic plasticity in the dentate gyrus. Proc Natl Acad Sci U S A 103:17501-17506. CrossRef Medline

Schmidt-Hieber C, Jonas P, Bischofberger J (2004) Enhanced synaptic plasticity in newly generated granule cells of the adult hippocampus. Nature 429:184-187. CrossRef Medline

Shepherd JD, Bear MF (2011) New views of Arc, a master regulator of synaptic plasticity. Nat Neurosci 14:279-284. CrossRef Medline

Snyder JS, Choe JS, Clifford MA, Jeurling SI, Hurley P, Brown A, Kamhi JF, Cameron HA (2009) Adult-born hippocampal neurons are more numerous, faster maturing, and more involved in behavior in rats than in mice. J Neurosci 29:14484-14495. CrossRef Medline

Snyder JS, Soumier A, Brewer M, Pickel J, Cameron HA (2011) Adult hippocampal neurogenesis buffers stress responses and depressive behaviour. Nature 476:458-461. CrossRef Medline

Toni N, Laplagne DA, Zhao C, Lombardi G, Ribak CE, Gage FH, Schinder AF (2008) Neurons born in the adult dentate gyrus form functional synapses with target cells. Nat Neurosci 11:901-907. CrossRef Medline

Tronel S, Belnoue L, Grosjean N, Revest JM, Piazza PV, Koehl M, Abrous DN (2012) Adult-born neurons are necessary for extended contextual discrimination. Hippocampus 22:292-298. CrossRef Medline

Trouche S, Bontempi B, Roullet P, Rampon C (2009) Recruitment of adultgenerated neurons into functional hippocampal networks contributes to updating and strengthening of spatial memory. Proc Natl Acad Sci U S A 106:5919-5924. CrossRef Medline

van Praag H, Schinder AF, Christie BR, Toni N, Palmer TD, Gage FH (2002) Functional neurogenesis in the adult hippocampus. Nature 415:1030-1034. CrossRef Medline

Vukovic J, Colditz MJ, Blackmore DG, Ruitenberg MJ, Bartlett PF (2012) Microglia modulate hippocampal neural precursor activity in response to exercise and aging. J Neurosci 32:6435-6443. CrossRef Medline

Wang S, Scott BW, Wojtowicz JM (2000) Heterogenous properties of dentate granule neurons in the adult rat. J Neurobiol 42:248-257. CrossRef Medline

Wesierska M, Dockery C, Fenton AA (2005) Beyond memory, navigation, and inhibition: behavioral evidence for hippocampus-dependent cognitive coordination in the rat. J Neurosci 25:2413-2419. CrossRef Medline

Zhang CL, Zou Y, He W, Gage FH, Evans RM (2008) A role for adult TLX-positive neural stem cells in learning and behaviour. Nature 451: 1004-1007. CrossRef Medline

Zhang J, Giesert F, Kloos K, Vogt Weisenhorn DM, Aigner L, Wurst W, Couillard-Despres S (2010) A powerful transgenic tool for fate mapping and functional analysis of newly generated neurons. BMC Neurosci 11: 158. CrossRef Medline

Zhao C, Teng EM, Summers RG Jr, Ming GL, Gage FH (2006) Distinct morphological stages of dentate granule neuron maturation in the adult mouse hippocampus. J Neurosci 26:3-11. CrossRef Medline 